\title{
USO DE TECNOLOGIAS DIGITAIS EM PESQUISAS DE OPINIÃO: DISCUSSÕES SOBRE O COMPONENTE AFETIVO DO LETRAMENTO ESTATÍSTICO A PARTIR DO MODELO DE IDDO GAL
}

\author{
USE OF DIGITAL TECHNOLOGIES IN OPINION SURVEYS: \\ DISCUSSIONS ON THE AFFECTIVE COMPONENT OF STATISTICAL \\ LITERACY FROM THE IDDO GAL'S MODEL
}

\author{
Felipe Júnio de Souza Oliveira ${ }^{1}$ \\ Diogo Alves de Faria Reis ${ }^{2}$
}

\begin{abstract}
Resumo: Neste artigo, fizemos um recorte da pesquisa de mestrado intitulada "Letramento estatístico na educação básica: o uso de tecnologias digitais em pesquisas de opinião" para apresentarmos e discutirmos alguns aspectos do componente afetivo do letramento estatístico, na perspectiva do modelo de Gal (2002). Nossas discussões estão ambientadas na realização de um projeto educativo de pesquisa de opinião, inspirado na metodologia do programa Nossa Escola Pesquisa Sua Opinião (Nepso), em que 16 alunos do $8^{\circ}$ ano do ensino fundamental utilizaram tecnologias digitais (TD) como Whatsapp, Facebook e Excel para investigarem sobre uma temática que os interessasse e, com isso, desenvolvessem conhecimentos estatísticos. Em nosso processo de análise, percebemos, dentre outras coisas, que, numa aprendizagem estatística, o foco não pode ser só a própria Estatística, mas um conjunto de competências e habilidades, incluídas as estatísticas, que se relacionam aos interesses, necessidades, valores e práticas sociais das pessoas envolvidas.
\end{abstract}

Palavras-chave: Educação Estatística; Letramento Estatístico; Pesquisa de opinião; Nepso; Tecnologias Digitais.

\begin{abstract}
In this paper, we present a part of the master's research entitled " Statistical literacy in basic education: the use of digital technologies in opinion surveys" to discuss some aspects of the affective component of statistical literacy, from the perspective of the Gal's (2002) model. Our discussions are subsidized by realization an educational project of opinion survey, inspired by the methodology of the program Nossa Escola Pesquisa Sua Opinião (Nepso), in which 16 students of 8th year fundamental school useded digital technologies such as WhatsApp, Facebook and Excel to investigate on a theme that would interest them and, with that, develop statistical knowledge. In our process of analysis, we realize, among other things, that in a statistical learning, the focus can not be just Statistics itself, but a set of competences and abilities, including statistics, that relate to interests, needs, values and social practices of the people involved.
\end{abstract}

Keywords: Statistical Education; Statistical Literacy; Opinion Survey; Nepso; Digital Technologies.

\footnotetext{
${ }^{1}$ Mestre em Educação e Docência, na linha de Educação Matemática, pela Universidade Federal de Minas Gerais (UFMG). Professor da Rede Municipal de Belo Horionte, Minas Gerais, Brasil. E-mail: felipej.oliveira@yahoo.com.br

${ }^{2}$ Doutor em Educação, na linha de Educação Matemática, pela Universidade Federal de Minas Gerais (UFMG). Professor do Núcleo de Matemática do Centro Pedagógico e do Programa de Pós-Graduação em Educação e Docência da Faculdade de Educação da Universidade Federal de Minas Gerais (Promestre FaE/UFMG), Belo Horizonte, Minas Gerais, Brasil. E-mail: diogofaria.ufmg@gmail.com
} 


\section{Discussões iniciais}

Em dezembro de 2018, o Instituto Brasileiro de Geografia e Estatística (IBGE) divulgou dados da Pesquisa Nacional por Amostra de Domicílios Contínua (a chamada Pnad Contínua) com o tema "Tecnologia da Informação e Comunicação"3. Nesta pesquisa, os resultados mostraram que mais de dois terços da população brasileira com mais de 10 anos de idade $(69,8 \%)$ utilizaram, com frequência, a internet e seus produtos tecnológicos digitais (softwares, aplicativos, redes sociais, dentre outros), sendo que o percentual para faixas etárias de 14 a 29 anos ultrapassa os 82,5\% da população.

Ainda segundo essa pesquisa, o equipamento mais utilizado pelas pessoas para acesso às tecnologias digitais (TD), conectadas via internet, foi o smartphone, representando 98,7\% dos usuários. Dentre as finalidades mais comuns, o consumo e o envio de informações por meio de aplicativos de mensagens instantâneas como o Whatsapp e redes sociais destacou-se com mais de $95 \%$ em todas as regiões brasileiras.

Divulgações como essas do IBGE reforçam que a exposição precoce e excessiva às informações disponíveis em diversos meios de comunicação, com atenção especial aos digitais (portais eletrônicos de notícias, redes sociais, newsletters ${ }^{4}$, dentre outros), "urge que a escola cumpra seu papel de educar para a cidadania”, de acordo com Lopes (2008, p. 60). Essa autora diz ainda que dados e conceitos estatísticos são utilizados a todo momento, como em questões sociais, econômicas, políticas, dentre outras, e que, dessa forma, é fundamental preparar os cidadãos para uma atuação reflexiva, ponderada e crítica em suas práticas sociais. Bacich, Tanzi Neto e Trevisani (2015, p. 48) acrescentam que "pela facilidade de acesso à informação, novas formas de aprendizagem surgem, com conhecimentos sendo construídos coletivamente e compartilhados com todos a partir de um clique no mouse".

Dessa forma, Oliveira (2019) e o seu orientador, primeiro e segundo autores deste artigo, respectivamente, realizaram uma pesquisa de mestrado objetivando investigar e analisar o uso de TD (possíveis contribuições e limitações) em um projeto educativo de pesquisa de opinião cujo foco foi um processo de aprendizagem estatística de alunos do oitavo ano do ensino fundamental. Sob o título "Letramento estatístico na educação básica: o uso de tecnologias digitais em pesquisas de opinião", descrevemos e analisamos

\footnotetext{
${ }^{3}$ Esses e outros dados interessantes da pesquisa do IBGE sobre o uso da internet no Brasil podem ser acessados em: https://biblioteca.ibge.gov.br/index.php/biblioteca-catalogo?view=detalhes\&id=2101631. O nosso acesso foi realizado em 28 de abril de 2019.

${ }^{4}$ Boletins informativos sobre determinado assunto com distribuição regular para assinantes.
} 


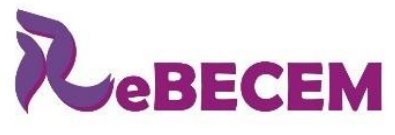

DOI: http://dx.doi.org/10.33238/ReBECEM.2019.v.3.n.2.22449
Revista Brasileira de Educação em

Ciências e Educação Matemática

a participação dos alunos nesse projeto baseado na abordagem de aprendizagem do programa ${ }^{5}$ Nossa Escola Pesquisa Sua Opinião (Nepso).

O Nepso foi essencial para o nosso trabalho de investigação e, por isso, esse programa, destinado à difusão da pesquisa de opinião como instrumento de trabalho pedagógico, teve destaque nos nossos referenciais teóricos. Com base nas suas oito etapas, que serão discutidas na segunda seção deste artigo, concebemos um projeto educativo de pesquisa de opinião. Este projeto viabilizou a realização do nosso trabalho de campo e oportunizou as nossas discussões em torno das circunstâncias que nos colocamos a investigar sobre o uso de TD, suas contribuições e limitações, em pesquisas de opinião realizadas numa escola de educação básica.

Cientes do irrefreável crescimento do uso das tecnologias digitais no consumo, produção e divulgação de informações sobre incontáveis assuntos e preocupados, na perspectiva do letramento estatístico, com o desenvolvimento crítico dos alunos diante dessa abundância de informações, apresentaremos, na próxima subseção, algumas das justificativas sobre as quais nos baseamos para propor as discussões presentes neste artigo, oriundas da dissertação supracitada. Elas serão apresentadas de forma resumida sem, no entanto, descaracterizar a importância dos assuntos tratados. Além disso, evidenciaremos a questão central da pesquisa que desenvolvemos e alguns objetivos que pretendíamos alcançar em nossa experiência.

Para este artigo, fizemos um recorte da pesquisa de mestrado na intenção de propormos algumas discussões sobre o componente afetivo do letramento estatístico na perspectiva de Gal (2002), uma das principais referências adotadas para analisar os nossos dados. Para tanto, explicitaremos os objetivos específicos deste texto, apresentaremos o Nepso como uma abordagem pedagógica e o letramento estatístico como uma competência fundamental da Educação Estatística (EE), fazendo-se uma opção pelo modelo de Gal (2002).

Também, faremos uma síntese do percurso metodológico e do processo de análise que empregamos para, então, prosseguirmos com uma apreciação dos dados relativos a um dos oito encontros que foram feitos na pesquisa de campo. Ao finalizarmos, apresentaremos algumas considerações e percepções acerca do componente afetivo do letramento.

\footnotetext{
${ }^{5}$ O termo "programa" é utilizado com o significado de conjunto de ações e projetos relacionados entre si, com alguns objetivos comuns.
} 
DOI: http://dx.doi.org/10.33238/ReBECEM.2019.v.3.n.2.22449

Para iniciar a próxima subseção, esclareceremos os campos curricular e científico em que a nossa pesquisa foi situada, escolhendo-se uma interseção da Educação Matemática (EM) com a Educação Estatística (EE).

\subsection{Delimitação curricular e científica, questão de pesquisa e síntese das justificativas}

Há pouco mais de 20 anos, no final da década de 1990, o ensino da Estatística foi oficialmente incluído no currículo de Matemática no Brasil com a publicação dos Parâmetros Curriculares Nacionais (PCN). De fato, foi a primeira vez que esse conteúdo ganhou destaque como proposta programática para a educação básica brasileira. No âmbito do bloco denominado Tratamento da Informação, ou Análise de Dados no caso do ensino médio, além da Estatística, a Probabilidade e a Combinatória ganharam diretrizes curriculares que tornaram obrigatória a inserção dessas temáticas na sala de aula de Matemática.

Essa inserção, em grande parte, deu-se em virtude de um movimento mundial, a partir da década de 1970, que criticava a cultura determinística nas aulas de Matemática e defendia a importância do desenvolvimento do raciocínio probabilístico e estatístico e as dimensões política, social e ética destas áreas na educação básica (CAZORLA; UTSUMI, 2010). Uma das consequências desse movimento foi a consolidação da área de atuação pedagógica e de pesquisa denominada Educação Estatística, cujo objetivo é estudar e compreender os modos pelos quais as pessoas ensinam e aprendem Estatística, bem como os aspectos cognitivos, afetivos e socioculturais do ensino-aprendizagem que interferem nesses processos, a epistemologia conceitual e didática, o desenvolvimento de métodos e materiais de ensino.

Constituída por pesquisadores de programas de pós-graduação em EM, Educação ou áreas afins, a EE "se valeu do avanço das pesquisas em Educação Matemática, mas mostrou que, apesar de conjugarem muitos aspectos comuns, apresentam diferenças importantes" (CAMPOS; WODEWOTZKI; JACOBINI, 2013, p. 12, grifos nossos). Essas diferenças, basicamente, estão relacionadas à didática, aos métodos e aos princípios como os de aleatoriedade e incerteza da Estatística que se diferenciam dos aspectos mais lógicos e/ou determinísticos da Matemática.

Lopes (2008) enfatiza que um dos papéis delegados ao ensino de Matemática, para além do domínio dos números, é o compromisso do trabalho com organização de dados, 


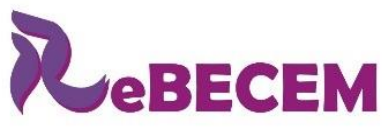

DOI: http://dx.doi.org/10.33238/ReBECEM.2019.v.3.n.2.22449
Revista Brasileira de Educação em

Ciências e Educação Matemática

leitura de gráficos e análises estatísticas em que o contexto fornece significados. Nesse sentido, Santos (2015, p. 20) propõe que o cenário “explicita uma relação muito próxima entre a produção em Educação Matemática e Educação Estatística, sem, no entanto, que isso se configure como uma relação de domínio no campo teórico de uma área (Educação Matemática) sobre a outra (Educação Estatística)".

Isso quer dizer que, para analisar a formação elementar em Estatística, o foco e as perspectivas teórico-metodológicas precisam estar articulados com a EM, tendo em vista que essa formação se dá nas aulas de Matemática, conforme destaca Lopes (2010b). Considerando as interfaces entre essas áreas, essa autora afirma haver uma interseção que se justifica no currículo de Matemática da educação básica.

Diante disso e ciente de que a Estatística é ministrada, predominantemente, por professores que ensinam Matemática no âmbito da educação básica, Santos (2015, p. 20, grifo do autor), diz que "isto não implica, necessariamente, uma relação de inclusão (no sentido comumente tomado na Teoria dos Conjuntos) entre as duas áreas no campo teórico". Como áreas de investigação, esse autor defende uma configuração de interseção entre EM e EE em que, ora compartilham problemáticas, ora tratam de questões particulares, dependendo do objeto de estudo. Ele ainda acrescenta que, por serem ensinadas por um mesmo profissional e partilhar pressupostos e preceitos de vários campos (epistemologia, filosofia, axiologia, cognição, dentre outros), "seria difícil estabelecer uma conjuntura em que estas duas áreas sejam, no campo teórico, mutuamente exclusivas (também no sentido comumente tomado na Teoria dos Conjuntos)" (SANTOS, 2015, p. 21, grifos do autor). Essas ideias estão compiladas na Figura 1.

Figura 1: Relação entre a EM e a EE como áreas de investigação

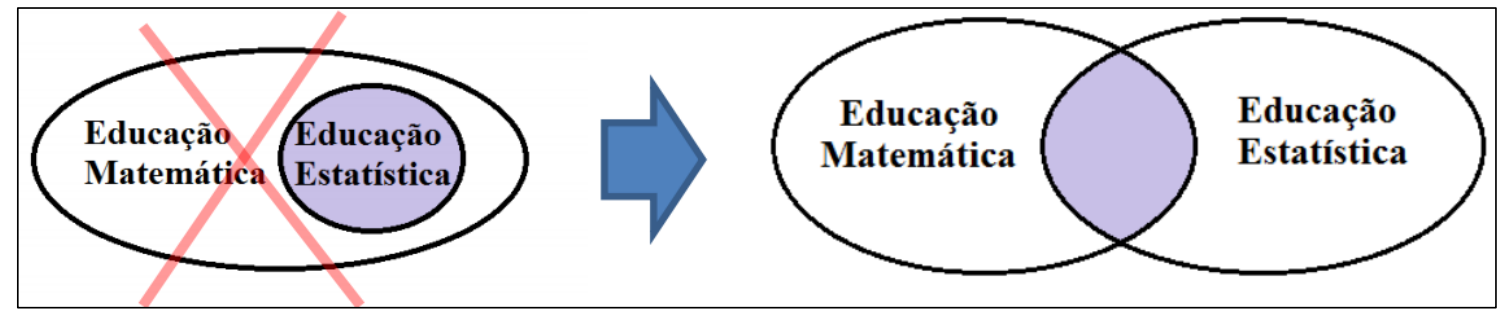

Fonte: Santos (2015)

Dessa forma, compreendemos que a nossa investigação foi situada nessa interseção entre a EM e a EE sem, no entanto, deixar de reconhecer que a primazia do assunto tratado localizou-se na EE. Com isso, propusemos a seguinte questão de pesquisa: quais contribuições e limitações podem haver no uso de tecnologias digitais em pesquisas de opinião do Nepso para uma aprendizagem em Estatística de alunos do $8^{\circ}$ ano? 
DOI: http://dx.doi.org/10.33238/ReBECEM.2019.v.3.n.2.22449

O interesse e a estruturação da nossa pesquisa em torno dessa questão deram-se, especialmente, por três motivos: importância do desenvolvimento estatístico elementar; potencialidades do uso de tecnologias digitais na educação; e relevância do Nepso como uma abordagem de aprendizagem por meio do projeto educativo de pesquisa de opinião. A cada um desses motivos, resumidamente, apresentamos as seguintes argumentações.

A formação escolar básica em Estatística desempenha um papel de grande importância no mundo, pois, diante da grande quantidade de informações veiculadas pelos diversos meios de comunicação, é necessário analisar criticamente os dados que são apresentados. Isto se dá para que, por exemplo, haja clareza sobre os assuntos, para que as decisões que interfiram no cotidiano das pessoas sejam tomadas de forma eficiente e fundamentada e para que o cidadão tenha instrumentos para questionar e contraargumentar a credibilidade das notícias. Em outras palavras, Lopes (2010a, p. 50) fala em "cidadania com responsabilidade social".

Os PCN (BRASIL, 1998) preconizavam a importância da construção de competências e habilidades estatísticas relativas ao denominado Tratamento da Informação ao longo do processo de escolarização, articuladas à realidade e às experiências dos alunos, sob a justificativa da "abundância de informações e às formas particulares de apresentação dos dados com que se convive cotidianamente" (p. 134), além de "possibilitar o desenvolvimento de formas particulares de pensamento e raciocínio para resolver determinadas situações-problema que envolvem fenômenos aleatórios” (p. 134), por meio de uma linguagem estatística. Recentemente, com a promulgação da Base Nacional Comum Curricular (BNCC) pelo governo brasileiro, o bloco Tratamento da Informação passou a ser denominado pela unidade temática Probabilidade e Estatística em que os estudos são centrados na incerteza e no tratamento de dados (BRASIL, 2017).

Na BNCC, o discurso focal na formação para o mundo do trabalho é deslocado para o desenvolvimento de competências - mobilização de conhecimentos, habilidades, atitudes e valores - com ênfase na investigação e no desenvolvimento de projetos. Nessa lógica, a base curricular destaca a importância do uso das tecnologias para avaliar, comparar resultados, construir gráficos e medidas de tendência, a relevância do trabalho de planejamento, coleta, organização e comunicação dos dados sobre temáticas do interesse dos alunos e argumenta que "fazer julgamentos bem fundamentados e tomar as decisões adequadas" (BRASIL, 2017, p. 272) são necessários para descrever, explicar e predizer fenômenos nos quais a Estatística é utilizada. 


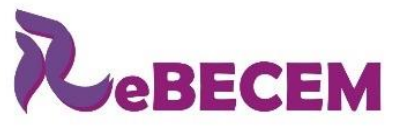

Revista Brasileira de Educação em

Ciências e Educação Matemática

DOI: http://dx.doi.org/10.33238/ReBECEM.2019.v.3.n.2.22449

Por esse ângulo, tendo em vista que as TD podem potencializar as possibilidades de utilização dos espaços, dos tempos e dos recursos disponíveis, o uso de recursos digitais como ferramenta aliada é alicerçado no fato de que grande parte dos alunos da educação básica é nativa digital (BACICH; TANZI NETO; TREVISANI, 2015), ou seja, são indivíduos que já nasceram numa cultura digital e cujas relações com as tecnologias foram absorvidas intuitivamente e marcam a forma de relacionamento com o conhecimento. Por isso as escolas, bem como os sistemas de ensino, necessitam passar por transformações que vinculem o aprendizado escolar às realidades sociais dos estudantes, incluindo a virtual. Além disso, Costa e Lopes (2008) dizem que, por meio da tecnologia, o professor pode diversificar e incrementar suas aulas, possibilitando uma maior compreensão dos fundamentos estatísticos, tornando-os mais significativos para realidade do aluno.

Também, buscamos discutir e propor novas formas de trabalho com a Estatística. Por isso, empenhamo-nos para um processo que oferecesse bases para um ensinoaprendizagem contextualizado e que permitisse o desenvolvimento da autonomia participativa dos alunos. Nesse sentido, optamos pela metodologia do programa Nepso, que consiste na difusão da pesquisa de opinião como ferramenta pedagógica em escolas públicas. É uma maneira de ensinar aos alunos a fazer pesquisa educativa de opinião, utilizando-se os dados coletados em atividades escolares.

Araújo e Deodato (2015, p. 4), ao relatarem uma experiência com alunos do $6^{\circ}$ ano, afirmaram que a "vivência do processo de tratamento da informação é uma característica central das pesquisas de opinião" e, portanto, do Nepso. Também nessa perspectiva, Faria et al., (2013, p. 4) dizem que "um dos objetivos pedagógicos da pesquisa de opinião na escola é exatamente promover o desenvolvimento de habilidades relativas ao Tratamento da Informação, instrumentalizando o educando para a compreensão dos conceitos e procedimentos matemáticos envolvidos”. Segundo Lima et al., (2010), o trabalho com projetos educativos de pesquisa de opinião, como o Nepso, que impliquem coleta, tabulação, análise e comunicação de dados sobre tema relevantes para os alunos, favorece a aquisição de conhecimentos matemáticos significativos. Esses autores afirmam que a pesquisa de opinião é ferramenta importante para incentivar o surgimento de novas propostas para as interações em sala de aula e, com elas, transpor o modelo da transmissão e oferecer a base para a produção de saberes. 


\subsection{Objetivos para este artigo}

De forma geral, para a pesquisa que desenvolvemos no mestrado, objetivamos investigar e analisar o uso das TD (suas contribuições e limitações) em um projeto educativo de pesquisa de opinião para um processo de aprendizagem em Estatística de alunos do oitavo ano do ensino fundamental. No entanto, para este artigo, buscamos:

- Comunicar parte do desenvolvimento e dos resultados da nossa pesquisa de mestrado;

- Discutir alguns aspectos do componente afetivo do letramento estatístico na perspectiva de Gal (2002);

- Apresentar algumas considerações baseadas na análise dos dados oriundos do primeiro e segundo encontros do projeto educativo de pesquisa de opinião baseado no Nepso.

\section{Nepso: a pesquisa de opinião que ensina}

O programa Nossa Escola Pesquisa Sua Opinião ou Nepso, como é mais conhecido, foi criado em 2000 como fruto de uma parceria entre o Instituto Paulo Montenegro (IPM) ${ }^{6}$ e a ONG Ação Educativa ${ }^{7}$ ao investigar como a pesquisa de opinião poderia ajudar a melhorar a qualidade do ensino e da aprendizagem no Brasil. A partir daquele ano, o IPM criou polos e núcleos multiplicadores em várias regiões do Brasil, América Latina e Europa para disseminação do programa, orientação e formação de educadores na metodologia do Nepso. Em Minas Gerais, desde 2002, a partir do "Projeto de Ensino Fundamental de Jovens e Adultos”, o Nepso ganhou um polo - Polo MG - por meio de uma parceria com a Faculdade de Educação da Universidade Federal de Minas Gerais (FAE/UFMG).

Ele é composto por ações e por uma metodologia de aprendizagem que consistem na disseminação do uso da pesquisa de opinião como instrumento pedagógico em escolas públicas. Trata-se de uma abordagem, sistematizada num manual ${ }^{8}$, que contempla um conjunto de ferramentas que visam, principalmente, propor:

\footnotetext{
${ }^{6}$ Organização sem fins lucrativos criada pelo IBOPE em 2000. Desenvolve e executa projetos socioeducativos.

${ }^{7}$ Organização não governamental fundada em 1994 com a missão de promover os direitos humanos nos campos da educação, da cultura e da juventude.

${ }^{8}$ Publicação que orienta os professores a realizarem projetos com pesquisas de opinião com a apresentação de conceitos básicos, discussões e etapas de uma pesquisa educativa na escola. Disponível em www.nepso.net.
} 
[...] o desenvolvimento de projetos de pesquisa educativa de opinião propiciando aprendizagens significativas, que vêm ao encontro das orientações curriculares atuais para a Educação Básica. Promove experiências de prática escolar que concretizam os princípios da contextualização de conteúdos, integração de disciplinas, valorização da iniciativa e autonomia dos jovens, cidadania e participação, afirmados nessas orientações, criando possibilidades de inovação do trabalho pedagógico (NEPSO, 2017, p. 1).

Para o desenvolvimento de um projeto educativo de pesquisa de opinião, o Nepso sugere oito etapas de trabalho que não são estanques e devem ser adaptadas de acordo com os objetivos de aprendizagem que se deseja, perfil da turma, tempo disponível, dentre outras variáveis. Portanto, não há um sentido único e rígido de ação pedagógica. Cada uma das etapas, com suas competências e habilidades, conduzem para os seguintes aspectos importantes na construção de uma pesquisa de opinião: escolha do tema; qualificação do tema; definição da população e da amostra; elaboração dos questionários; trabalho de campo; tabulação e processamento das informações; análise e interpretação dos resultados; sistematização, apresentação e divulgação. Na nossa dissertação, cada etapa é conceituada e discutida em termos das competências e habilidades que podem ser alcançadas em um projeto de aprendizagem com o Nepso.

Numa perspectiva de aprendizagem por investigação, entendemos as pesquisas de opinião do Nepso como forma de contribuição para o desenvolvimento de um trabalho diferenciado, cooperativo e estimulante. As reflexões que tecemos ao longo da pesquisa permitiram-nos uma concepção de que a metodologia do projeto educativo de pesquisa de opinião desse programa está amparada na pedagogia dos projetos de aprendizagem, que são uma poderosa oportunidade de envolver os alunos num aprendizado que é deles, por eles e com eles.

\section{Letramento estatístico: da competência fundamental ao modelo de Gal}

De forma ampla, mas que introduz muito bem a nossa concepção geral sobre letramento, está em Soares (1998). Na obra "Letramento: um tema em três gêneros", a autora apresenta um ensaio que trata, também, da dimensão social do letramento ao afirmar que:

[...] ele não é um atributo unicamente ou essencialmente pessoal, mas é, sobretudo, uma prática social: letramento é o que as pessoas fazem com as habilidades de leitura e de escrita, em um contexto específico, e como essas habilidades se relacionam com as necessidades, valores e práticas sociais. Em outras palavras, letramento não é pura e simplesmente um conjunto de habilidades individuais; é o conjunto de práticas sociais ligadas à leitura e à 
DOI: http://dx.doi.org/10.33238/ReBECEM.2019.v.3.n.2.22449

escrita em que os indivíduos se envolvem em seu contexto social (SOARES, 1998, p. 72, grifo da autora).

No âmbito da EE, o letramento estatístico é uma das competências mais discutida e analisada pelos autores que produzem artigos, dissertações, teses e outras publicações de pesquisa relacionadas a essa área do conhecimento. Em diferentes contextos, esse tema é tratado com diferentes enfoques, baseando-se, muitas vezes, nos objetivos e resultados desejados para um determinado nível de ensino para o qual é proposta uma abordagem didática que esteja amparada por uma teoria. Porciúncula e Samá (2015) ressaltam que o letramento consiste no horizonte do que se tem buscado consolidar na Educação Estatística.

Gal (2002, p. 1, tradução nossa) diz que o letramento estatístico é uma espécie de habilidade-chave cujo desenvolvimento é desejado nos cidadãos que vivem em sociedades saturadas de informações. Esse autor afirma que "o letramento estatístico é retratado como a capacidade de interpretar, avaliar criticamente e comunicar informações e mensagens estatísticas".

De acordo com Cazorla e Utsumi (2010, p. 12), o modelo de letramento proposto por Gal (2002) envolve dois componentes: o cognitivo e o afetivo. O primeiro, formado por cinco elementos, responsável pela competência das pessoas para compreender, interpretar e avaliar criticamente as informações estatísticas. O segundo, composto por dois elementos, responsável por moldar as visões de mundo do indivíduo e pela propensão para um comportamento questionador diante de informações estatísticas. Essas autoras sugerem um esquema sintetizador dessas ideias, conforme apresentamos na seguinte figura. 
DOI: http://dx.doi.org/10.33238/ReBECEM.2019.v.3.n.2.22449

Figura 2: Esquema que sintetiza os componentes do letramento estatístico propostos por Gal (2002)

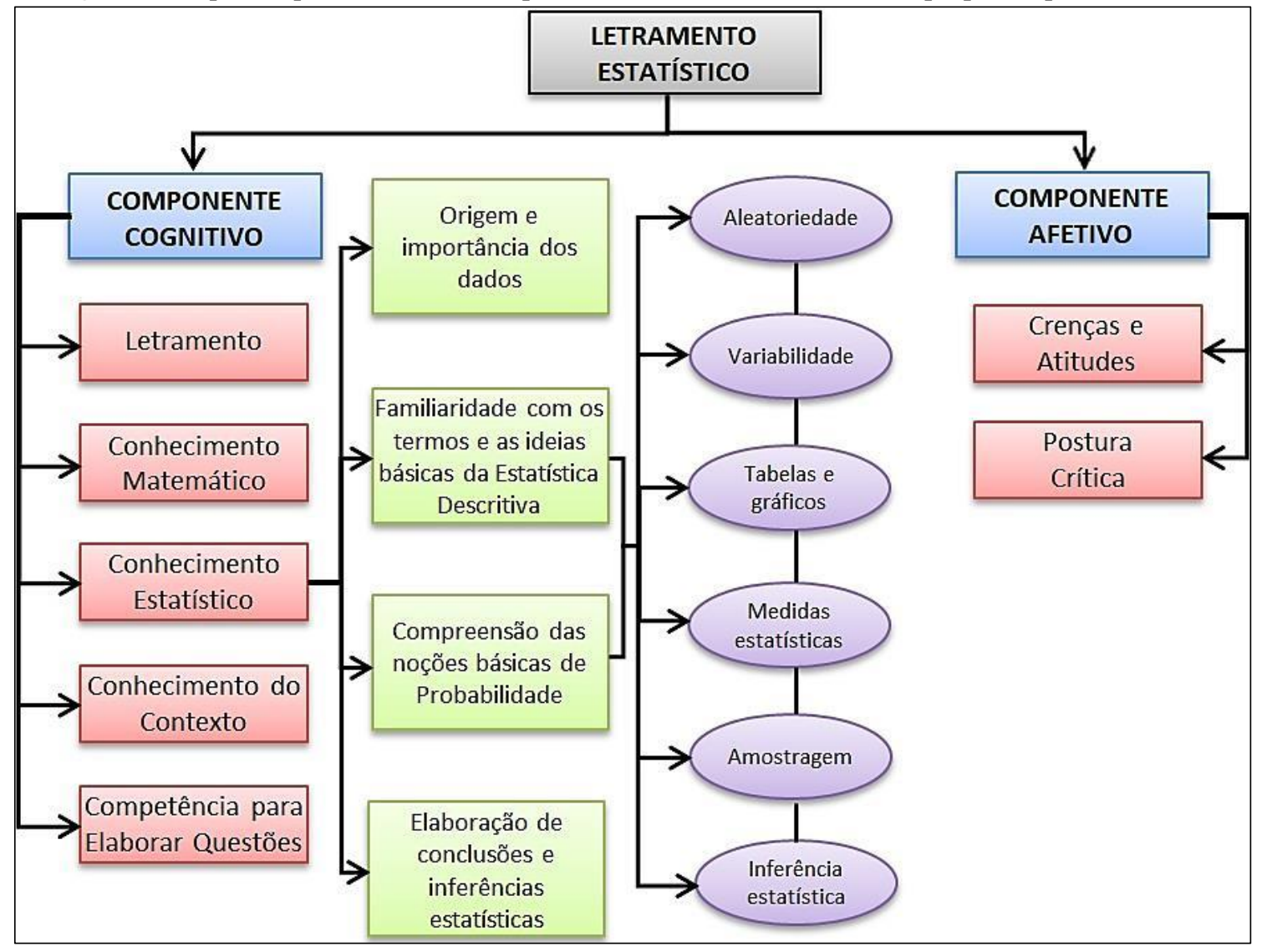

Fonte: Cazorla e Utsumi (2010, p. 12), com adaptações visuais

Em referência a essa definição proposta por Gal (2002), Cazorla, Kataoka e Silva (2010) acrescentam que essa capacidade, como prática social, leva em conta os argumentos que são relacionados aos dados ou aos fenômenos apresentados em qualquer contexto e que não se limita ao aspecto de leitura do mundo que a Estatística nos possibilita, mas também ao desenvolvimento do espírito investigativo. Assim, assumimos o letramento estatístico como competência fundamental para aprendizagem estatística, pois ansiamos por uma EE preocupada com o desenvolvimento de uma cidadania crítica, reflexiva, questionadora e autônoma dos nossos alunos.

\section{Síntese do percurso metodológico e do processo de análise}

Nossa pesquisa foi de natureza qualitativa tendo em vista que o contexto estudado e os sujeitos envolvidos, com suas características próprias e suas particularidades, são indissociáveis. A investigação sobre "quais contribuições e limitações podem haver no uso de tecnologias digitais em pesquisas de opinião do Nepso para uma aprendizagem em Estatística de alunos do $8^{\circ}$ ano?" requereu que os processos e os seus significados, levando em consideração a perspectiva dos participantes, fossem os focos principais, 
DOI: http://dx.doi.org/10.33238/ReBECEM.2019.v.3.n.2.22449

\section{ISSN 2594-9179}

característica marcante desse tipo de abordagem, segundo os autores Silva e Menezes (2005).

Assim como Fiorentini e Lorenzato (2006) caracterizam e descrevem as principais fases de uma pesquisa em educação, concebemos o trabalho de pesquisa em etapas que foram relacionadas e dependentes. Elas estão sintetizadas na seguinte figura.

Figura 3: Fases do trabalho de pesquisa
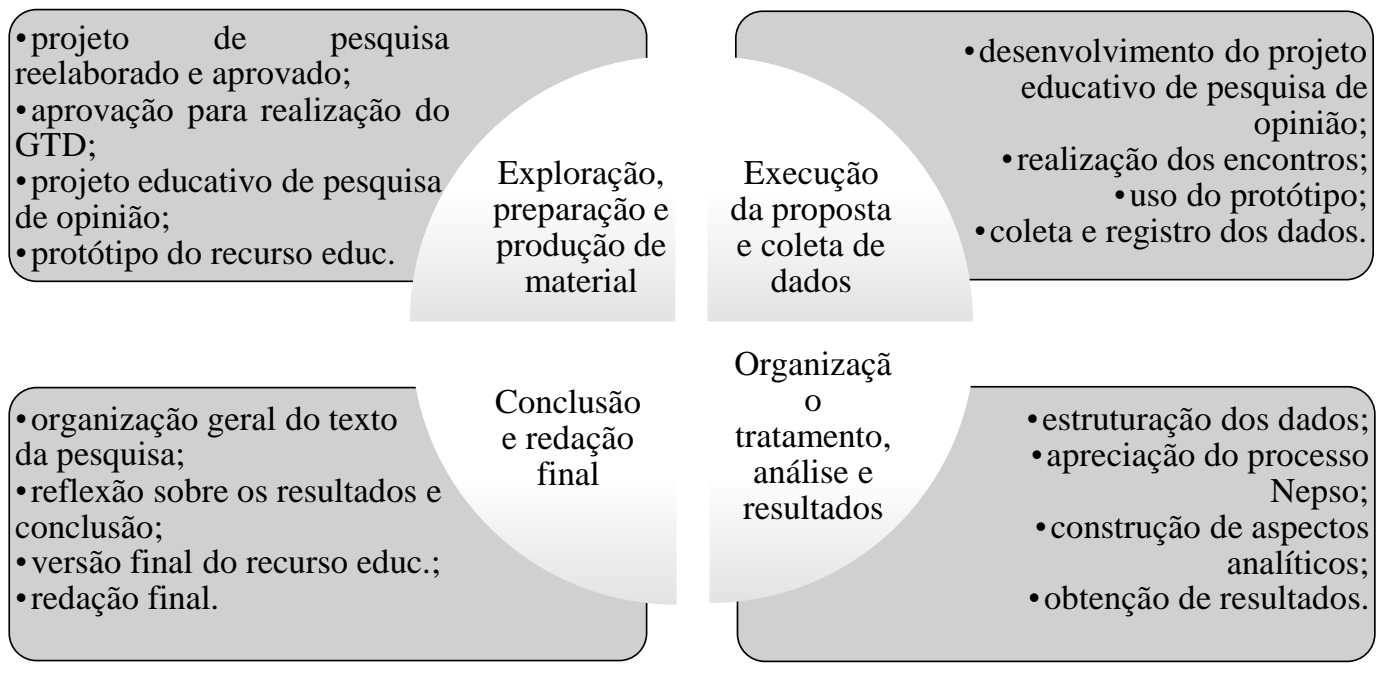

Fonte: Oliveira (2019)

$\mathrm{Na}$ fase de execução da proposta e coleta de dados, utilizamos alguns instrumentos de coleta e registro dos dados como diário de campo, gravação em áudio e vídeo dos encontros e registro digital de algumas tarefas realizadas por meio de um grupo de discussões criado no Whatsapp. Esses instrumentos mostraram-se adequados e suficientes para nossos registros. A fase de conclusão e redação final permitiu-nos perceber um processo de pesquisa contínuo, interligado em todas as etapas, descritivo, analítico, interpretativo e reflexivo.

Na pesquisa de campo, trabalhamos na perspectiva da observação participante (FIORENTINI; LORENZATO, 2006) durante o desenvolvimento do projeto educativo de pesquisa de opinião. Os encontros desse projeto foram pensados assumindo uma postura do professor-pesquisador como mediador do processo de aprendizagem e dos alunos como corresponsáveis pela pesquisa educativa e na organização e produção de conhecimento. Em todos os momentos, os alunos foram incentivados à negociação de interesses, reflexão, colaboração e discussão sobre todas as etapas do Nepso realizadas. 


\subsection{Um breve contexto da pesquisa e dos seus sujeitos}

Para a realização da pesquisa de campo, optamos pelo colégio de aplicação Centro Pedagógico (CP) da UFMG. Como exemplo da experimentação de novas práticas pedagógicas, o CP integra ao currículo escolar dos alunos o chamado Grupo de Trabalho Diferenciado - GTD. Esse grupo surgiu na busca por novas alternativas da organização dos tempos e espaços escolares do Centro Pedagógico tendo em vista a flexibilização e a dimensão pedagógica singularizada apresentada nos ciclos de formação (GOULART, 2005). Para cada ano do ciclo de formação, são oferecidos três horários que devem ser preenchidos com GTD distintos. A formação dos grupos ocorre por meio da manifestação de interesse dos alunos que podem escolher, a partir de uma lista organizada pelas coordenações dos ciclos, três opções de GTD para cada dia da semana disponibilizado.

Para o nosso trabalho de pesquisa, optamos por oferecer um GTD no Centro Pedagógico chamado “Tecnologias Digitais na Matemática”. Este Grupo, naturalmente, ficou vinculado ao núcleo de Matemática e, além de mim, teve como responsável o orientador desta pesquisa, o professor Diogo Alves de Faria Reis, do CP. Em sala de aula como professor, atuei com os alunos no desenvolvimento dos encontros. Nosso públicoalvo para esse trabalho foram 16 alunos do oitavo ano do ensino fundamental, integrantes do terceiro ciclo de formação do CP.

A nossa organização para o GTD centralizou-se em um projeto educativo de pesquisa de opinião como forma do planejamento pedagógico do trabalho que foi desenvolvido e da pesquisa de campo. Ao todo, realizamos 14 encontros dos quais utilizamos os 8 primeiros como recorte para a coleta, a análise e a interpretação de dados para a produção do relatório de pesquisa que compôs a dissertação. As atividades e estratégias do projeto educativo foram subsidiadas pelas orientações e metodologia do programa Nepso, o que atribuiu ao trabalho um caráter de investigação educativa por meio da pesquisa de opinião. Os encontros aconteceram em um dos laboratórios de informática da FAE/UFMG. No quadro a seguir, há um resumo dos encontros.

Quadro 1: Encontros da etapa de investigação educativa com pesquisa de opinião

\begin{tabular}{|c|l|}
\hline Encontro & \multicolumn{1}{|c|}{ Descrição sucinta das tarefas realizadas } \\
\hline $1^{\circ}$ & $\begin{array}{l}\text { Dinâmica para apresentação das pessoas e da proposta do GTD. Entrega dos termos para } \\
\text { participação. }\end{array}$ \\
\hline $2^{\mathbf{o}}$ & $\begin{array}{l}\text { Leitura e debate de textos com a formação de grupos. Proposição da criação de um grupo do } \\
\text { Whatsapp e início da etapa de escolha do tema. }\end{array}$ \\
\hline $3^{\mathbf{o}}$ & $\begin{array}{l}\text { Negociação de um tema, enfoques e questões de interesse nas etapas de escolha do tema e } \\
\text { qualificação do tema. }\end{array}$ \\
\hline
\end{tabular}


DOI: http://dx.doi.org/10.33238/ReBECEM.2019.v.3.n.2.22449

\begin{tabular}{|c|c|}
\hline $4^{\circ}$ & $\begin{array}{l}\text { Leitura e debate de texto sobre abordagens para o trabalho de campo. Delimitação do público } \\
\text { participante na etapa de definição da amostra e uso do protótipo do material de apoio ao } \\
\text { professor que ensina Matemática na elaboração do questionário on-line com as questões de } \\
\text { interesse. Etapa de trabalho de campo com a aplicação do questionário via redes sociais. }\end{array}$ \\
\hline $5^{\circ}$ & $\begin{array}{l}\text { Etapa de tabulação, processamento e tratamento dos dados com o auxílio do Facebook e do } \\
\text { Excel. }\end{array}$ \\
\hline $6^{\circ}$ & $\begin{array}{l}\text { Etapa de tabulação, processamento e tratamento dos dados com o auxílio do Facebook e do } \\
\text { Excel e início da análise e interpretação dos dados e resultados. Uso de filtros e tabelas de } \\
\text { duas entradas. }\end{array}$ \\
\hline $7^{\circ}$ & Conclusão dos tratamentos, análise e interpretação. Etapa de sistematização dos resultados. \\
\hline $8^{\circ}$ & $\begin{array}{l}\text { Apresentação e divulgação dos resultados da pesquisa educativa de opinião. Debate sobre o } \\
\text { tema. }\end{array}$ \\
\hline
\end{tabular}

Fonte: Oliveira (2019)

\subsection{Síntese do processo de análise dos dados}

Como julgamos importante preservar o Nepso como um processo de aprendizagem significativo e elementar para nosso trabalho, optamos por não fragmentar as nossas análises em "caixas" de categorias. Contudo, nos comprometemos com uma apreciação sistemática e orgânica do que chamamos de "processo Nepso" e, por isso, estudamos os dados, com os aspectos de análise e as reflexões teóricas, no âmbito das etapas desse programa desenvolvidas ao longo da pesquisa de campo.

Entendemos que esse processo, com suas etapas e características, não devia ser fragmentado, sob pena de abandonarmos a conexão de enredos de uma abordagem de aprendizagem em prol de estratos de análise. Sendo assim, escolhemos analisar os nossos dados (falas transcritas, textos produzidos, tarefas realizadas, interações, expressões gestuais, imagens e anotações do diário de campo) de forma descritiva e interpretativa, coerente com a natureza qualitativa da nossa pesquisa (SILVA; MENEZES, 2005), buscando destacar detalhes importantes que nos ajudaram a refletir sobre a nossa questão de investigação. Em outras palavras, visando uma costura de percepções e sentidos, procuramos relacionar alguns acontecimentos nos encontros da pesquisa educativa de opinião aos seguintes aspectos analíticos: 1. Contribuições e limitações das TD no projeto educativo de pesquisa de opinião; 2. Desenvolvimento de competências e habilidades relativas ao projeto de aprendizagem baseado no Nepso; 3. Habilidades e aspectos do letramento estatístico.

Nossa proposta foi identificar, analisar e interpretar esses aspectos analíticos com os autores referenciados em cada um dos encontros subsidiados pelas etapas do Nepso, não quebrando, assim, a sequência lógica das mesmas e preservando o processo do programa. Estávamos cientes de que esses aspectos poderiam não aparecer, 


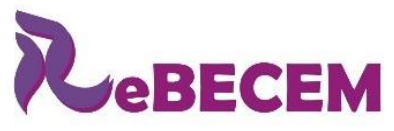

DOI: http://dx.doi.org/10.33238/ReBECEM.2019.v.3.n.2.22449
Revista Brasileira de Educação em

Ciências e Educação Matemática

simultaneamente, num mesmo encontro em virtude da programação de atividades para cada momento. O seguinte esquema ilustra o nosso processo de análise dos dados.

Figura 4: Processo de análise dos dados - O Nepso como um processo

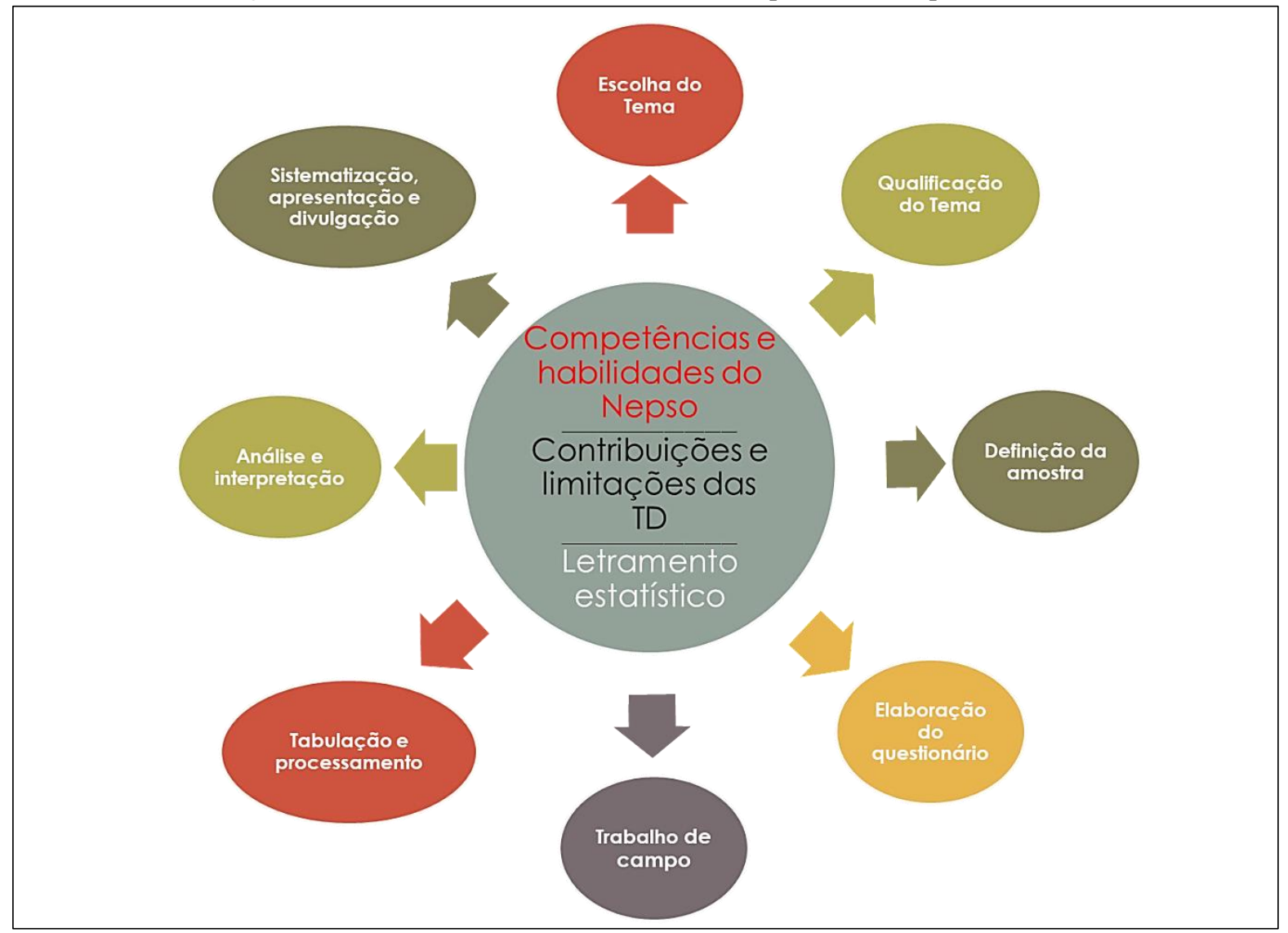

Fonte: Elaborada pelos autores

\section{Algumas análises na perspectiva do componente afetivo do letramento estatístico}

Para este artigo, destacamos as discussões e análises realizadas em torno dos acontecimentos do primeiro encontro do GTD "Tecnologias Digitais na Matemática". Novamente, fazemos um convite para a leitura da dissertação subsidiária deste texto, pois nela há mais detalhes sobre todo o nosso percurso de pesquisa.

\subsection{Primeiro encontro do Grupo de Trabalho Diferenciado (GTD)}

Na nossa análise sobre o primeiro encontro, gostaríamos de chamar a atenção para dois aspectos relacionados à expectativa dos alunos em relação ao GTD "Tecnologias Digitais na Matemática": o ambiente em que os encontros ocorreram e o modelo no qual desenvolvemos o trabalho planejado. Além disso, queremos descrever, brevemente, e analisar a dinâmica em que houve a apresentação de cada participante do grupo e a 
DOI: http://dx.doi.org/10.33238/ReBECEM.2019.v.3.n.2.22449

sondagem inicial sobre o conhecimento dos alunos quanto ao Nepso e às tecnologias digitais que utilizaríamos ao longo desse GTD.

Neste encontro, tivemos o primeiro contato com os 16 alunos que participariam do grupo que ofertamos. O coordenador do terceiro ciclo apresentou-nos a sala de aula destinada ao GTD e nos instruiu sobre a chegada dos alunos a partir das 13h10. Esta sala era pequena, com carteiras menores e, talvez, um pouco inadequadas para jovens de 13 anos. Havia um ventilador, mas o dia estava bastante quente e estávamos próximos a algumas áreas com barulho intenso. Portanto, decidimos acolher e organizar os alunos e nos dirigir ao laboratório de informática da FAE/UFMG, local também reservado ao nosso GTD. Este laboratório, bem como o prédio da FAE/UFMG, localiza-se em frente ao Centro Pedagógico e, por isso, levávamos cerca de cinco minutos de um local ao outro.

Ao chegarmos ao laboratório, enquanto os alunos escolhiam seus lugares, escutávamos algumas coisas em relação ao ambiente que era descoberto por eles:

\begin{abstract}
Quando chegamos ao lab [laboratório], os alunos correram para escolher os lugares e fizeram certo tumulto para assentarem próximos de quem eles queriam. Enquanto se organizavam naquela sala ainda desconhecida por eles (no caminho para a FAE, quase todos disseram não conhecer muita coisa do prédio da Faculdade de Educação nem os laboratórios de info [informática]), fomos escutando coisas assim: "sala legal”, "aqui está bem mais fresco que no $\mathrm{CP}$, agora dá pra estudar", "um note por pessoa, que sonho!", "uau, aqui tem wi-fi de graça" e "aqui tem aquela tela que dá pra fazer desenhos com a mão. Nunca vi isso no CP.." (nota do diário de campo do dia 15/03/2018).
\end{abstract}

Neste momento, percebemos que eles tentavam expressar alegria e descrever, de alguma forma, um novo ambiente. O laboratório de informática era bastante confortável e possuía ar condicionado, cadeiras giratórias grandes, duas ilhas de mesas com 14 notebooks cada, datashow, tela interativa de projeção e rede sem fio de internet. Além disso, o local era bastante silencioso e, quase sempre, ganhava o aroma da lanchonete que ficava bem próxima. Alguns alunos externaram ${ }^{9}$ as suas impressões sobre o laboratório por meio do nosso grupo fechado do Whatsapp quando estávamos conversando sobre a utilidade da sala para o nosso trabalho:

Aluno J: Eu achei a sala onde o nosso GTD foi realizado muito boa. Eu acho que a sala influenciou na questão do ar condicionado e os computadores. $\mathrm{O}$ cheiro de salgados deixava a gente com fome mas era bom tbm.

Aluno H: Na minha opinião a sala onde aconteceu o GTD foi melhor do que no $\mathrm{CP}$, pois ela parecia ser mais preparada para este tipo de atividade e etc.

\footnotetext{
${ }^{9}$ Optamos por manter erros nos registros escritos e indicar correções entre colchetes quando necessário.
} 
DOI: http://dx.doi.org/10.33238/ReBECEM.2019.v.3.n.2.22449

Aluna A: Simm, mudar de ambiente às vezes muda nosso jeito de pensar, e ajudou também para o nosso futuro quando formos trabalhar em um ambiente profissional. Ou seja, no futuro...

Aluno O: Eu achei que a sala onde nós estávamos trabalhando era muito boa, ou dizer excelente perto de qualquer outra do $\mathrm{CP}$, disponibilizando muitas coisas para nós, para que nós conseguimos [conseguíssemos] trabalhar com nossos gráficos. Como eu falei o ambiente influenciou sim, de forma que a gente conseguisse trabalhar o que tiamos [tínhamos] que trabalhar. Ex: os computadores / notbooks [notebooks], internet rápida e várias outras coisas.

Aluna F: Eu acho que a sala que ficamos durante as aulas nos ajudaram pois as pesquisas que fizemos nos computadores ficaram bem mais fáceis. Imagina fazer aquilo à mão. Acho que além de nos proporcionar uma rapidez para os trabalhos, qualquer dúvida que poderíamos ter e vc tiver ocupado, poderíamos usar a internet para tirar dúvidas (trecho das postagens dos Alunos J, H, A, O e F, grupo do Whatsapp).

Do nosso ponto de vista, essas falas revelam uma situação de bem estar que influenciou a participação dos alunos ao longo do GTD e propiciou comportamentos de desejo e prazer por estarem nesse ambiente, interagindo com os seus pares. Sobre esse aspecto, queremos dialogar com um modelo para o letramento estatístico proposto por Gal (2002), especialmente no tocante ao componente afetivo. Um fragmento desse modelo, que está representado integralmente na Figura 2, está reproduzido a seguir.

Figura 5: Fragmento do modelo de letramento estatístico proposto por Gal (2002), com detalhes para o componente afetivo

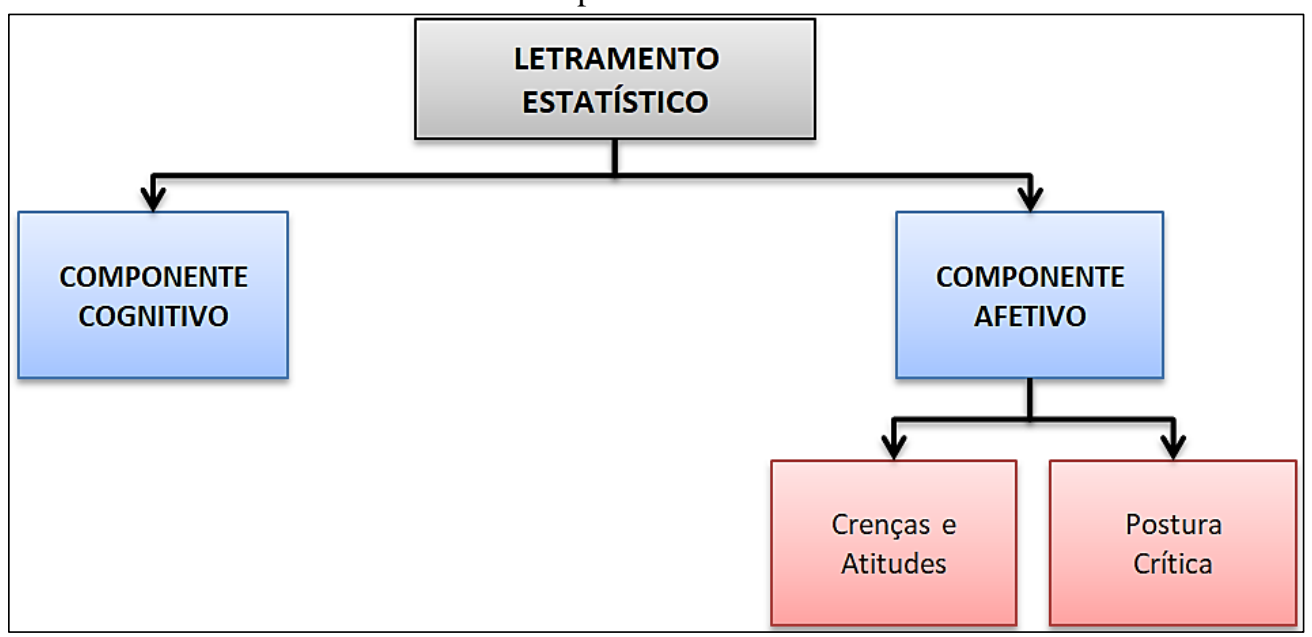

Fonte: Adaptado de Cazorla e Utsumi (2010, p. 12)

De acordo com Gal (2002, p. 18, tradução nossa), “certas crenças e atitudes estão na base da postura crítica e da disposição das pessoas em investir esforços mentais ou ocasionalmente assumir riscos como parte de atos do letramento estatístico". Em relação às atitudes, esse autor diz que elas são relativamente estáveis, construídas e/ou desencadeadas, também, por respostas emocionais do contexto num determinado tempo e são expressas ao longo de um continuum positivo-negativo (gostar - não gostar, 
DOI: http://dx.doi.org/10.33238/ReBECEM.2019.v.3.n.2.22449

agradável - desagradável) que podem representar sentimentos em relação a objetos, ações ou aprendizagens (GAL, 2002).

Nessa perspectiva, sentir-se seguro, à vontade, acolhido e confortável para o desenvolvimento de um trabalho de investigação educativa com pesquisa de opinião, no nosso caso específico, favoreceu a exploração, a proposição e a revisão de crenças e a convivência saudável com um estado de incerteza (GAL, 2002), necessários para a consolidação de uma postura crítica frente às informações estatísticas. Portanto, falas como "acho que a sala influenciou na questão do ar condicionado e os computadores", "ela parecia ser mais preparada para este tipo de atividade", "mudar de ambiente às vezes muda nosso jeito de pensar, e ajudou também para o nosso futuro", "disponibilizando muitas coisas para nós, para que nós conseguimos [conseguíssemos] trabalhar com nossos gráficos" e "as pesquisas que fizemos nos computadores ficaram bem mais fáceis. Imagina fazer aquilo à mão", nos fazem acreditar que o componente afetivo do letramento estatístico, conforme o modelo de Gal (2002), foi influenciado pelo ambiente e funcionou como fator motivacional para os trabalhos realizados no laboratório de informática acerca do projeto educativo de pesquisa de opinião.

Ademais, a partir da fala da aluna $\mathrm{F}$, percebemos um reconhecimento quanto à importância da presença das tecnologias digitais nesse espaço. Segundo ela, os cálculos, tabelas, gráficos e análises, tarefas desenvolvidas nos encontros, foram facilitados por esses recursos ao dizer "Imagina fazer aquilo à mão". Ela ainda acrescenta que "além de nos proporcionar uma rapidez para os trabalhos, qualquer dúvida que poderíamos ter e vc [você] tiver ocupado, poderíamos usar a internet para tirar dúvidas", reconhecendo algumas características das TD contemporâneas como rapidez, portabilidade e multifuncionalidade (BORBA; SILVA; GADANIDIS, 2015; BACICH; TANZI NETO; TREVISANI, 2015; ESTEVAM; KALINKE, 2013).

Outro ponto que nos chamou a atenção assim que começamos a nos organizar para a primeira tarefa do encontro foi o questionamento de dois alunos sobre o modelo de aula e o funcionamento do GTD:

Ainda antes de começarmos a primeira tarefa (dinâmica), dois alunos começaram a me questionar se usaríamos o caderno, se deveria ser dividido com o de Matemática, quantas folhas seriam, se escreveríamos muito igual nas aulas de Matemática deles. Respondi que, provavelmente, não usaríamos o caderno, pois nossas atividades seriam no laboratório. Eles vibraram e disseram que começamos com o pé direito, pois eles copiaram muito neste dia de muito calor. Quando disse que não usaríamos caderno, senti que eles se entusiasmaram em fazer algo diferente de copiar. Pareceu-me que a expectativa deles era de que o GTD seria uma espécie de aula mecanizada de 
DOI: http://dx.doi.org/10.33238/ReBECEM.2019.v.3.n.2.22449

Matemática, apesar do título e da ementa do grupo (nota do diário de campo do dia 15/03/2018).

Uma postagem reforçou a nossa suspeita sobre essa expectativa deles e nos colocou a refletir sobre uma possível visão de que só o professor influencia o aprendizado: "eu não acho que este ambiente influenciou no nosso aprendizado, pois quem [influencia] é o professor e não o ambiente" (Aluno H, grupo do Whatsapp). Diante dessa situação, buscamos comentar algo sobre o uso do caderno e o porquê de não o utilizarmos, a princípio, nos nossos encontros:

\begin{abstract}
Professor-pesquisador: Eu achei engraçado, por que eu não tinha pensado nessa pergunta [...], mas alguns de vocês me perguntaram se a gente ia utilizar caderno, né. É, e eu achei engraçado por que eu não tinha pensado que vocês poderiam ter essa dúvida se a gente utilizaria caderno ou não, por que eu já tinha vindo com a ideia assim, olha, então hoje mesmo a gente já vai começar no laboratório de informática pra eles já sentirem o ambiente que a gente vai trabalhar e pra gente já deixar o nosso planejamento claro. [...] é comum quando a gente participa de alguma atividade educativa que a gente utilize o caderno pra fazer registro, né, de alguma coisa. O caderno funciona como uma espécie de diário em que a gente vai fazendo as anotações ali que são importantes e algumas também que não são importantes, mas que são registros que nos auxiliam no caso da aprendizagem. [...] o caderno é uma espécie de tecnologia também. Ele não é uma tecnologia digital, mas ele é uma espécie de tecnologia. Uma tecnologia que serve para registro, né, para anotação. Mas o nosso propósito não é trabalhar essa tecnologia, esse tipo de tecnologia no nosso GTD. A gente vai trabalhar tecnologias digitais no nosso GTD (trecho de transcrição da gravação em áudio do dia 15/03/2018).
\end{abstract}

Nesse sentido, concordamos com Bacich, Tanzi Neto e Trevisani (2015) e Lima et al., (2010) sobre as potencialidades existentes na relação entre docentes, alunos e TD de forma a possibilitar a colaboração e a atuação protagonista dos sujeitos da sala de aula, abandonando o modelo de ensino mecanizado. Lima et al., (2010, p. 25) ainda afirmam que "esse modelo [do ensino mecanizado] vem dando sinais de esgotamento ao longo do tempo e, atualmente, diante das novas tecnologias da informação e da comunicação, ele mostra-se cada vez mais inadequado". Para esses autores, transpor esse modelo significa interferir nos fenômenos educativos de tal forma a permitir a produção coletiva de conhecimentos sobre coisas do interesse dos envolvidos.

Entendemos, também, que a surpresa do professor-pesquisador ocorreu em função do desconhecimento da rotina na qual os alunos participantes do GTD estavam inseridos. Parte-se do pressuposto que esses sujeitos escolheram estar ali por algum motivo, aliado ao processo de organização dos grupos feita pelos professores. No entanto, esses motivos não foram objeto da nossa investigação. Mesmo assim, consideramos que as manifestações de contentamento dos estudantes nos revelaram, inicialmente, uma opção acertada da parte deles, especialmente ao ouvirmos comentários como "esse professor é 
DOI: http://dx.doi.org/10.33238/ReBECEM.2019.v.3.n.2.22449

tão legal" e "ah, é por isso que escolhi esse GTD. Ele é de tecnologias e Matemática", registrados nas notas do diário de campo do dia 15/03/2018.

Além desses dois aspectos relacionados às expectativas dos alunos em relação ao GTD, gostaríamos de descrever, brevemente, a dinâmica de apresentação que realizamos e que permitiu, rapidamente, conhecermos um pouco mais de cada um e promover um entrosamento. Basicamente, a dinâmica consistiu na formação de duplas em que cada pessoa deveria conhecer e apresentar ao grupo informações como nome, idade, o que gosta de fazer e etc., do seu companheiro.

A parte cômica da dinâmica foi o tempo previsto de cada apresentação: o tempo da queima de um palito de fósforo que era aceso pelo integrante da dupla assim que a fala era iniciada. Foi um momento de muita descontração e tensão, pois, para falar mais, eram feitos malabarismos para que o palito permanecesse aceso por mais tempo. A diversão de todos ficou mais completa quando coisas, muitas vezes segredos, eram contadas sem a permissão do colega. Ao final, fizemos uma síntese das apresentações e relembramos o nome de cada aluno.

Esse momento de dinâmica, reconhecimento e formação de equipe é uma iniciativa incentivada pelo Nepso ao se perceber que essa etapa é um primeiro passo para a concretização de uma ideia de projeto educativo de pesquisa de opinião. Além disso, "como a pesquisa requer trabalho coletivo, é fundamental a definição conjunta de objetivos e responsabilidades entre alunos, professores e outros participantes da comunidade escolar envolvidos no projeto" (LIMA et al., 2010, p. 51).

Logo que iniciamos, quisemos evidenciar que a participação dos alunos na construção do projeto educativo de pesquisa de opinião seria de fundamental importância, pois nossa concepção é a de que o Nepso se caracteriza como um projeto de aprendizagem. Portanto, nos preocupamos em esclarecer aos alunos que:

Professor-pesquisador: [o projeto] não é uma proposta fechada, porque eu quero escutar vocês, saber o que vocês acham. Na verdade, eu nem diria que é uma proposta pro GTD, por que o GTD vai ser construído por mim e por vocês ao mesmo tempo, tá? A única coisa que eu proponho, na verdade, pra esse GTD [...] é que a gente utilize as tecnologias pra buscar conhecimento e pra produzir conhecimento, tá? Então, o que na verdade eu trouxe não foi uma proposta fechada. Foi, na verdade, um esqueleto e a partir desse esqueleto é que a gente vai construir a nossa proposta de trabalho. Seria muito mais fácil se eu chegasse aqui e falasse "gente, nesse papelzinho aqui, tá escrito tudo o que a gente vai fazer do dia 15 até o último dia do GTD”, seria muito mais fácil, por que as regras já estariam colocadas, a formatação do nosso trabalho já estaria posta, mas só que é mais desafiador, é mais interessante, é mais construtivo, nós construirmos isso juntos, nós fazermos isso juntos, e nós propormos juntos (trecho de transcrição da gravação em áudio do dia 15/03/2018). 
Assim como existem competências e habilidades previstas para as oito etapas do programa Nepso, Lima et al. (2010) afirmam que, ao longo do planejamento e execução da proposta de trabalho, outras capacidades podem ser desenvolvidas. Para esses autores, participar na definição do projeto fazendo propostas, negociando quando houver expectativas divergentes, assumir responsabilidades, prever recursos materiais e humanos, além do tempo, ajudar a definir e cumprir tarefas sob uma coordenação de atividades e avaliar a própria participação e a dos demais quanto ao cumprimento de tarefas e acordos são algumas das competências e habilidades que podem ser percebidas.

Como nossa intenção era propor a criação de um grupo de discussões e atividades em alguma rede social on-line, pensamos no Facebook, inicialmente, por ser uma plataforma popular e de fácil gestão. No entanto, quando colocamos em debate esse assunto, percebemos que a preferência dos alunos era pelo Whatsapp pelos seguintes motivos que foram registrados por meio da gravação em áudio e no diário de campo:

Aluno O: No whats... todo mundo tem e gasta menos internet.

Aluna D: É, sem contar que todo mundo mexe mais e não trava. É mais rápido também. É mais fácil que o face [Facebook].

Aluna F: Professor, faz no Whatsapp mesmo. Aqui todo mundo tem e dá pra economizar nos dados. Chama de GTD e tá bom (trecho de transcrição da gravação em áudio do dia 15/03/2018).

Professor-pesquisador: sobre o fórum, de forma quase que unânime, eles [os alunos] manifestaram pelo Whatsapp ao invés do Facebook, pois eles achavam mais prático, rápido e com pouco consumo de dados do pacote deles. Preciso avaliar, pois o uso do Whatsapp não estava previsto. Eles disseram ainda que grupo de discussão no whats [Whatsapp] é mais usado. Fiquei impressionado com a argumentação, o posicionamento deles na escolha por essa opção e pela unanimidade... (nota do diário de campo do dia 15/03/2018).

Ao longo das análises dos encontros, exploraramos a usabilidade do Whatsapp nas interações e na realização das tarefas, no entanto, assim como ressaltam Bacich, Tanzi Neto e Trevisani (2015) e Oliveira (2018), é oportuno e interessante observarmos a facilidade com que os jovens, os chamados nativos digitais (BACICH; TANZI NETO; TREVISANI, 2015), apropriam-se, intuitivamente, dos possíveis usos das tecnologias digitais. Além disso, a argumentação dos alunos do GTD foi preponderante sobre as intenções iniciais do professor-pesquisador que pensava apenas nas facilidades em se optar pelo Facebook. Porém, sob a alegação da praticidade, economia no uso dos dados e a rapidez, os alunos influenciaram um replanejamento da proposta para o grupo de discussões que passou a ser hospedado no Whatsapp, conforme a demanda dos alunos. 


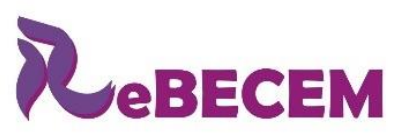

Revista Brasileira de Educação em

Ciências e Educação Matemática

DOI: http://dx.doi.org/10.33238/ReBECEM.2019.v.3.n.2.22449

Por outro lado, ao serem perguntados sobre o Excel, quase todos nunca haviam tido um contato mais próximo antes, apesar de alguns se lembrarem de já terem visto em algum lugar. Apenas um dos alunos afirmou já ter usado e saber que o seu pai usa constantemente no trabalho. Nesta sondagem, verificamos o pouco conhecimento dos alunos sobre o Excel, o que reforça o salientado por Chance et al., (2007), Estevam (2010) e Estevam e Kalinke (2013) sobre a finalidade comercial desse software. Contudo, esses mesmos autores evidenciam as potencialidades dessa ferramenta na aprendizagem estatística e, por isso, optamos por utilizá-la para o tratamento dos dados, dosando instruções aos alunos à medida que eles nos demandavam.

Além disso, perguntamos se eles conheciam o Nepso e já haviam trabalhado com essa metodologia no Centro Pedagógico ou em outra escola. Apenas uma aluna manifestou-se dizendo não conhecer o programa. Os demais conheciam, mas alguns disseram não se lembrarem, com exatidão, do que se tratava. Então, decidimos falar sobre o Nepso e suas etapas ao abordarmos a ementa, a proposta de trabalho e a programação do GTD.

Finalizamos este encontro com a entrega dos documentos autorizativos da participação dos alunos no GTD e sanamos algumas dúvidas que foram apresentadas.

\section{Algumas considerações}

$\mathrm{O}$ recorte da pesquisa de mestrado que propusemos preocupou-se em iniciar discussões acerca dos elementos do modelo para o letramento estatístico de Gal (2002) na perspectiva do componente afetivo. Para isso, apresentamos a análise do primeiro encontro, de oito encontros, de uma pesquisa educativa de opinião em que 16 alunos do oitavo ano do ensino fundamental utilizaram algumas tecnologias digitais como o Whatsapp, Facebook e Excel para investigarem sobre uma temática que os interessasse e, com isso, desenvolvessem conceitos e conhecimentos estatísticos.

Ao longo das análises do primeiro encontro considerado, bem como dos demais encontros que realizamos, depreendemos que para uma aprendizagem preocupada com o letramento, o foco não pode ser só a própria Estatística, mas um conjunto de competências e habilidades, incluídas as estatísticas, que se relacionem aos interesses, necessidades, valores e práticas sociais das pessoas. Assim como Cazorla e Utsumi (2010), partimos do pressuposto de que o letramento estatístico não se restringe apenas à leitura de mundo e, por isso, acreditamos que a participação ativa dos alunos na condução da escolha do tema, 


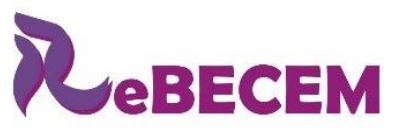

Revista Brasileira de Educação em

Ciências e Educação Matemática

DOI: http://dx.doi.org/10.33238/ReBECEM.2019.v.3.n.2.22449

dos enfoques e das questões de interesse, das variáveis, na coleta e análise dos dados, assumindo papéis, desenvolvendo a capacidade de arguição, aprendendo a ouvir as críticas e a respeitar a opinião dos outros, influenciou, de forma disposicional, o empenho deles na participação dos trabalhos. Supomos que essa postura crítica, em grande parte, foi oriunda desse processo de participação ativa que os qualificou a conhecer, com intimidade e de forma contextual, as informações que eles questionaram, levantaram hipóteses e inferiram interpretações.

Ao percebermos que a abordagem do programa Nepso tornou-se estruturante para a nossa pesquisa de campo com o projeto educativo desenvolvido e que características do letramento estatístico emergiam da proposta de aprendizagem em Estatística, não ignoramos as outras discussões que poderiam ser feitas. Partimos do pressuposto de que todas elas faziam parte de um mesmo processo que chamamos de "processo Nepso" que não poderia ser fragmentado sob pena de prejudicarmos a compreensão do que buscávamos e abandonarmos a conexão de uma abordagem de aprendizagem em prol de estratos de análise. Nesse sentido, analisamos os dados de forma processual, descrevendoos e interpretando-os, qualitativamente, visando atingir os nossos objetivos e dialogar sobre os aspectos analíticos que propusemos.

Na nossa concepção, a situação de bem estar dos alunos influenciou a participação deles ao longo do GTD e propiciou comportamentos de desejo e prazer por estarem nesse ambiente, interagindo com os seus pares. Assim, concluímos que se sentir seguro, à vontade, acolhido e confortável para o desenvolvimento de um trabalho de investigação educativa com pesquisa de opinião, no nosso caso específico, favoreceu a exploração, a proposição e a revisão de crenças e a convivência saudável com um estado de incerteza, necessários para a consolidação de uma postura crítica frente às informações estatísticas.

Além disso, percebemos que os alunos reconheceram a importância da presença das tecnologias digitais nos nossos encontros, detectando algumas características como rapidez, portabilidade e multifuncionalidade desses recursos. Também, a percepção de que outro modelo de aula estava proposto para o GTD (colaborativo com atuação protagonista dos sujeitos envolvidos) fez com que os alunos demonstrassem satisfação em estarem nesse espaço que eles escolheram estar, principalmente, motivados pela divulgação de que tecnologias digitais estariam presentes.

Em momentos oportunos, divulgaremos outras discussões da nossa pesquisa. No entanto, convidamos os leitores a acessarem o texto integral disponível na dissertação. 


\section{Referências}

ARAÚJO, D. A.; DEODATO, A. A. A pesquisa de opinião nas aulas de Matemática: reflexões sobre projetos desenvolvidos com alunos de $2^{\circ}$ ciclo. In: ENCONTRO MINEIRO DE EDUCAÇÃO MATEMÁTICA, 7., 2015, São João Del-Rei. Anais... São João Del-Rei: SBEMMG, 2015.

BACICH, L.; TANZI NETO, A.; TREVISANI, F. M. Ensino Híbrido: personalização e tecnologia na educação. In: BACICH, L.; TANZI NETO, A.; TREVISANI, F. M. (org.). Ensino Híbrido: personalização e tecnologia na educação. 1. ed. Porto Alegre: Penso, 2015. p. 47-65.

BORBA, M. C.; SILVA, R. S. R.; GADANIDIS, G. Fases das tecnologias digitais em Educação Matemática: sala de aula e internet em movimento. 2. ed. Belo Horizonte: Autêntica Editora, 2015.

BRASIL. Ministério da Educação. Parâmetros Curriculares Nacionais: Matemática. Brasília: Secretaria de Educação Fundamental, 1998.

BRASIL. Ministério da Educação. Base Nacional Comum Curricular - BNCC. Brasília: Secretaria de Educação Básica, 2017.

CAMPOS, C. R.; WODEWOTZKI, M. L. L.; JACOBINI, O. R. Educação Estatística: teoria e prática em ambientes de modelagem matemática. 2. ed. Belo Horizonte: Autêntica Editora, 2013.

CAZORLA, I. M.; KATAOKA, V. Y; SILVA, C. B. Trajetória e perspectivas da Educação Estatística no Brasil: um olhar a partir do GT12. In: LOPES, C. E.; COUTINHO, C. Q. S.; ALMOULOUD, S. A. (org.). Estudos e reflexões em educação estatística. 1. ed. Campinas: Mercado de Letras, 2010. p. 19-44.

CAZORLA, I. M.; UTSUMI, M. C. Reflexões sobre o ensino de Estatística na Educação Básica. In: CAZORLA, I.; SANTANA, E. (org.). Do tratamento da informação ao letramento estatístico. 1. ed. Itabuna: Via Litterarum, 2010. p. 9-18.

CHANCE, B. et al. The role of technology in improving student learning of statistics. Technology Innovations in Statistics Education Journal, Los Angeles, v. 1, n. 1, 2007.

COSTA, M. A. D.; LOPES, M. R. C. M. A Tecnologia da Informação e a Estatística no Ensino Fundamental. Curitiba, 2008. Disponível em: www.diaadiaeducacao.pr.gov.br. Acesso em: 22 maio. 2016.

ESTEVAM, E. J. G. (Res) significando a educação estatística no ensino fundamental: análise de uma sequência didática apoiada nas tecnologias de informação e comunicação. 2010. Dissertação (Mestrado em Educação) - Faculdade de Ciências e Tecnologia, Universidade Estadual Paulista, Presidente Prudente, 2010.

ESTEVAM, E. J. G.; KALINKE, M. A. Recursos tecnológicos e ensino de estatística na educação básica: um cenário de pesquisas brasileiras. Revista Brasileira de Informática na Educação, Porto Alegre, v. 21, n. 2, p. 104-117. 2013.

FARIA, J. B. et al. NEPSO das águas: pesquisa de opinião no estudo de temáticas relacionadas à água. In: UFMG JOVEM, 14., 2013, Belo Horizonte. Anais... Belo Horizonte: UFMG, 2013. 
DOI: http://dx.doi.org/10.33238/ReBECEM.2019.v.3.n.2.22449

FIORENTINI, D.; LORENZATO, S. Investigação em educação matemática: percursos teóricos e metodológicos. 1. ed. Campinas: Autores Associados, 2006.

GAL, I. Adult's statistical literacy: meanings, components, responsibilities. International Statistical Review, Haia/ Netherlands, v. 70, n. 1, p. 1-25, apr. 2002.

GOULART, S. M. G. A Matemática em uma escola organizada por ciclos de formação humana. 2005. Dissertação (Mestrado em Educação) - Faculdade de Educação, Universidade Federal de Minas Gerais, Belo Horizonte, 2005.

LIMA, A. L. D’ I. et al. NEPSO: manual do professor. 3. ed. São Paulo: Global, 2010.

LOPES, C. E. O ensino da estatística e da probabilidade na educação básica e a formação dos professores. Cadernos Cedes, Campinas, v. 28, n. 74, p. 57-73, jan./abr. 2008.

LOPES, C. E. Os desafios para Educação Estatística no currículo de Matemática. In: LOPES, C. E.; COUTINHO, C. Q. S.; ALMOULOUD, S. A. (org.). Estudos e reflexões em educação estatística. 1. ed. Campinas: Mercado de Letras, 2010a. p. 47-64.

LOPES, C. E. A educação estatística no currículo de matemática: um ensaio teórico. In: REUNIÃO ANUAL DA ANPED, 33., 2010b, Caxambu/MG. Anais... Caxambu/MG: Anped, 2010. p. 1-15.

NEPSO. Site do Programa NEPSO. Disponível em: <http://www.nepso.net>. Acesso em: 07 de maio de 2017.

OLIVEIRA, F. J. S. Abordagens pedagógicas no tratamento da informação. Revista Brasileira de Educação Básica, Belo Horizonte, v. 3, n. 8, p. 01-09, abr./jun. 2018.

OLIVEIRA, F. J. S. Letramento estatístico na educação básica: o uso de tecnologias digitais em pesquisas de opinião. 2019. Dissertação (Mestrado em Educação e Docência) - Faculdade de Educação, Universidade Federal de Minas Gerais, Belo Horizonte, 2019.

PORCIÚNCULA, M. M. S.; SAMÁ, S. Projetos de aprendizagem: uma proposta pedagógica para a sala de aula de Estatística. In: SAMÁ, S.; PORCIÚNCULA, M. M. S. (org.). Educação Estatística: ações e estratégias pedagógicas no ensino básico e superior. 1. ed. Curitiba: CRV, 2015. p. 133-141.

SANTOS, R. M. Estado da arte e história da pesquisa em educação estatística em programas brasileiros de pós-graduação. 2015. Tese (Doutorado em Educação) - Faculdade de Educação, Universidade Estadual de Campinas, Campinas, 2015.

SILVA, E. L.; MENEZES, E. M. Metodologia da pesquisa e elaboração de dissertação. 4. ed. Florianópolis: UFSC, 2005.

SOARES, M. Letramento em ensaio - Letramento: como definir, como avaliar, como medir. In: SOARES, M. Letramento: um tema em três gêneros. 1. ed. Belo Horizonte: Autêntica, 1998. p. 61-125.

Recebido em: 20 de maio de 2019.

Aceito em: 01 de agosto de 2019. 